\title{
Stringent delineation of Pallister-Hall syndrome in two long surviving patients: importance of radiological anomalies of the hands
}

Centre for Human Genetics, Liège University, CHU Sart Tilman, (B) 4000 Liège, Belgium A Verloes

Department of Paediatrics and Medical Genetics, CHU Nantes, France A David

Department of Paediatric Radiology, Geneva University Hospital and Medical School, Switzerland L Ngô

Division of Medical Genetics,

Geneva University

Hospital and Medical

School,

Switzerland

A Bottani

Correspondence to: Dr Verloes.

Received 25 November 1994 Revised version accepted for publication 9 March 1995

\author{
Alain Verloes, Albert David, Loan Ngô, Armand Bottani
}

\begin{abstract}
We report two unrelated, long surviving patients ( 2 and 17 years) with syndromal hypothalamic hamartoblastoma. Both showed mild facial dysmorphism (downward slanted palpebral fissures, ptosis, microretrognathia), cleft epiglottis, and developmental delay. The younger child had stenosis of the pulmonary arteries, complex urogenital malformations, and anal atresia. In the oldest patient, the hamartoma caused precocious puberty of the central type, combined with complete hGH deficiency. Both patients showed bony anomalies of the extremities: variable proximal synostosis between central (2nd to 4th) metacarpals or intercalary polydactyly with generalised brachydactyly, severe brachytelephalangism, syndactyly, and nail hypoplasia.

Together with the absence of anomalies of cholesterol metabolism, a combination of oral frenula, laryngeal malformations, digestive abnormalities, intercalary polysyndactyly, generalised brachytelephalangism, and nail hypoplasia should allow the delineation of Pallister-Hall syndrome, even when a CNS tumour is absent. The radiological abnormalities are helpful in differentiating Pallister-Hall syndrome from the other syndromes in which hypothalamic hamartoblastoma is observed. This is of major importance for genetic counselling, since Pallister-Hall syndrome may be a dominantly inherited disorder, thus contrasting with most of the other disorders with the CAVE phenotype, which are recessively inherited.
\end{abstract}

(F Med Genet 1995;32:605-611)

In 1980 , Hall et $a l^{1}$ reported six children with a multiple congenital abnormalities (MCA) syndrome. The main features were hypothalamic hamartoblastoma, various orofacial abnormalities (cleft, multiple frenula), laryngeal malformations, internal malformations, imperforate anus, aganglionosis, and digital anomalies. The delineation of the syndrome and the differential diagnosis with other disorders in which hypothalamic hamartoma is observed (table) have been the subject of several publications, but an unambiguous definition of the syndrome is still needed. We report here the clinical and radiological findings in two long surviving children with Pallister-Hall syn- drome, and suggest a narrower and more strict definition of this puzzling disorder.

\section{Case reports}

PATIENT 1

This male patient is the fifth child of unrelated, healthy parents. The father was aged 43 years at the birth of the child. Birth weight at 41 weeks of gestation was $2800 \mathrm{~g}$, birth length $45 \mathrm{~cm}$, and OFC $34 \mathrm{~cm}$. Seizures began at 2 months. Developmental milestones were delayed. He walked at 30 months. At $3 \frac{1}{2}$ years he was $80 \mathrm{~cm}$ tall $(-5 \mathrm{SD})$ and had an OFC of $48.5 \mathrm{~cm}$ ( $-1.5 \mathrm{SD})$. Neuroradiological investigations at this time showed a hypothalamic mass. Sequential CT scan showed that the tumour size had not increased and treatment was limited to anticonvulsant drugs.

He was referred to the paediatric department at the age of 10 for evaluation of precocious puberty manifest by the age of $9 \frac{1}{2}$. He was $114 \mathrm{~cm}$ tall $(-5 \mathrm{SD})$ and had an OFC of $51.5 \mathrm{~cm}$ ( $-2 \mathrm{SD}$ ) (fig 1 ). He showed mild dysmorphic features: triangular shaped face, marked frontal bossing, broad nasal bridge with normal inner intercanthal distance, mild ptosis, and downward slanting palpebral fissures (fig 1A). There were no buccal abnormalities, except for unerupted canine teeth. The hands (fig 1B) were short with brachytelephalangism, nail hypoplasia (fig 1C), and camptodactyly of fingers 3-5. The halluces were broad, the toe nails were more hypoplastic than the finger nails, and there was duplication of the 4th toe on the left side (fig 1D). Cleft epiglottis (without any difficulties in swallowing), double urethral meatus, and hypoplasia of the right kidney were noted. The heart was normal. Lymphocytic karyotype, serum cholesterol, and cholesterol metabolites were normal.

$X$ rays (fig 2A-D) showed a generalised brachydactyly with shortening of the metacarpals and phalanges ( $\mathrm{Z}$ score -5.5 (SD 2.3)). The reduction of the metacarpals and proximal phalanges was around $-4 \mathrm{SD}$, which is roughly proportional to the general growth retardation. The middle phalanges were proportionately shorter; the deviation appeared more marked in the 3rd and 4th fingers. The distal phalanges were minute, about $-8 \mathrm{SD}$, as illustrated by the metacarpophalangeal profile (MCPP) of the left hand (fig 3). On the right side, the 3rd and 4th metacarpals were proximally fused. The carpal bones were small and the distal epiphyses of the ulna and radius appeared somewhat misshapen. The poly- 
A

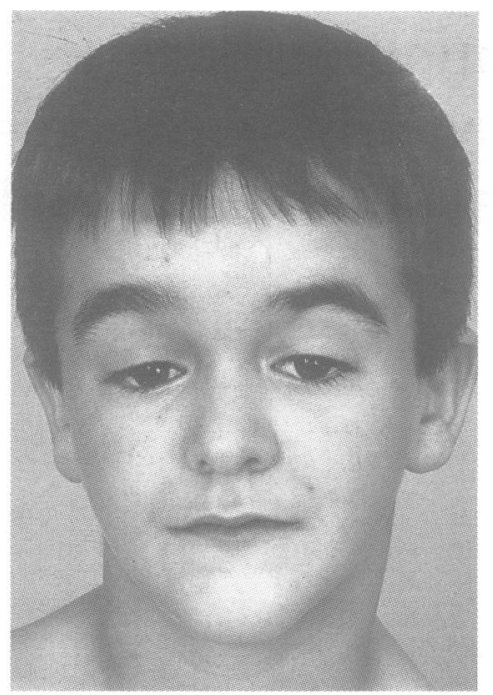

B

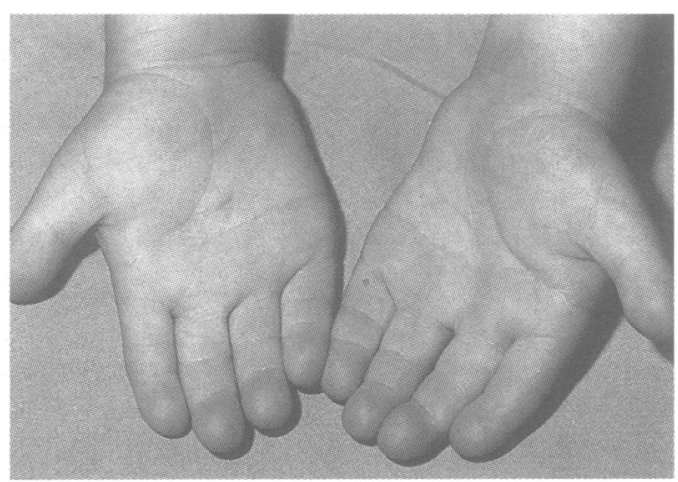

C

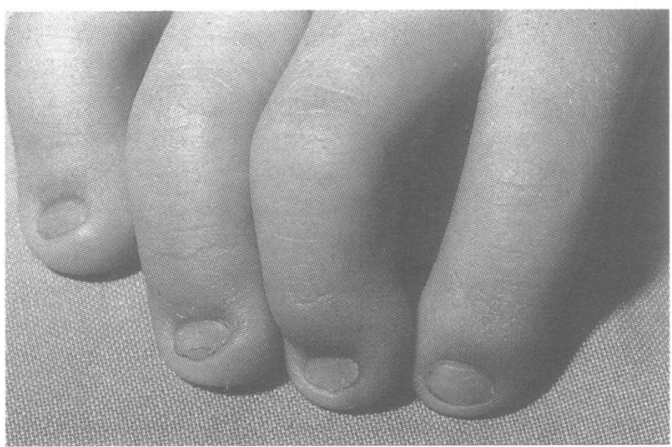

$\mathrm{D}$

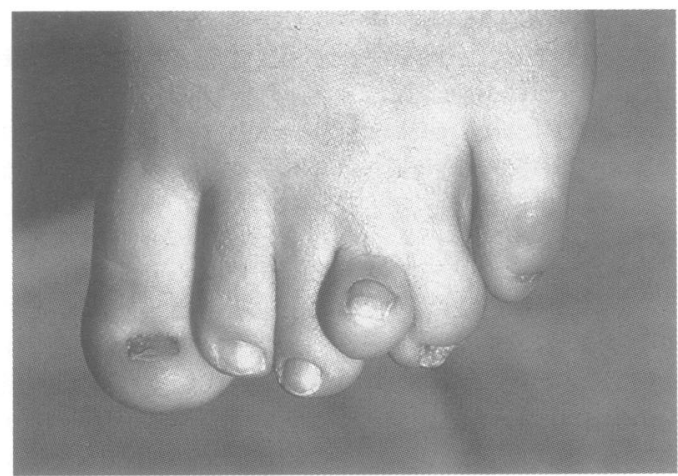

Figure 1 Patient 1 age 10. (A) Facial appearance, (B) brachydactyly, (C) right hand, nail dysplasia, (D) left foot, intercalated polydactyly and marked nail hypoplasialdysplasia.

dactyly of the foot was the result of an incompletely formed digit placed close to the 4th ray, with a dysplastic distal metatarsal and normal phalanges. Brain MRI scan (fig 4) confirmed a $3.2 \mathrm{~cm}$ wide mass extending from the cerebral peduncles toward the optic chiasma.
Endocrinological studies confirmed precocious puberty of central onset: $\mathrm{LH}$ reached $10.3 \mathrm{UI} / 1$ and FSH $3.7 \mathrm{UI} / 1$ with LHRH stimulation. Plasma testosterone level was $8870 \mathrm{ng} / \mathrm{l}$. There was complete GH deficiency, with a peak $<1.8 \mu \mathrm{g} / \mathrm{l}$ after both arginine-insulin and betaxolol-glucagon stimulation tests. Prolactin, ACTH, and TSH secretions were normal.

Treatment with long acting subcutaneous GHRH analogue was initiated, and led to a reduction of testosterone to prepubertal levels. Simultaneously, $\mathrm{GH}$ replacement was initiated. At the age of $16 \frac{1}{2}$, this patient is $149 \mathrm{~cm}$ tall $(-4 \mathrm{SD})$, and has an OFC of $55.3 \mathrm{~cm}$ $(-0.5 \mathrm{SD})$. His CNS tumour has not grown and his neurological examination remains normal. He is severely mentally retarded, with aggressive behaviour and a tendency to selfmutilation. Speech is limited to a few words.

\section{PATIENT 2}

This girl (fig 5A) was the second child of unrelated, healthy parents, both aged 33 years at the birth of their daughter. The father had bilateral postaxial polydactyly of the hands removed in early infancy. The pregnancy was unremarkable. Amniocentesis done to alleviate parental anxiety was normal. Caesarean section was performed at 38 weeks of gestation because of fetopelvic disproportion. Growth retardation (birth weight $2330 \mathrm{~g}$ ) and prenatal onset short stature (birth length $42.5 \mathrm{~cm}$ ) were evident. OFC was normal $(33 \mathrm{~cm})$. Mild facial dysmorphism was noted: a flat profile, short forehead, short nose with flat nasal bridge and anteverted nares, and micrognathia. There was a cleft palate, but neither oral frenula nor lingual hamartoma. Anal atresia and a blind ending rectoperineal fistula were present. The hands were very short with telebrachydactyly: digits $2-5$ were conical and of even length, the nails were hypoplastic, the thumbs were proximally implanted, stubby, and adducted (fig $5 \mathrm{~B}, \mathrm{C}$ ). Movement at the interphalangeal joints was limited and there was only one IP flexion crease. On the left side, there was a complete 4-5 and partial 3-4 cutaneous syndactyly. The feet were similarly affected (fig 5 $D, E)$ with generalised shortness, brachydactyly, dorsiflexed and proximally set big toes, and nail hypoplasia. The right foot was more severely involved than the left: there was complete cutaneous syndactyly of toes 4-5, adduction of toes 2 and 3, and a wide gap between toes 3 and 4. Extensive study in the perinatal period disclosed the following internal malformations: bifid epiglottis, malacia of the cervical part of the trachea, regional constriction of the oesophagus (attributed to an aberrant venous compression), hiatus hernia, probable common mesentery, severe stenosis of the pulmonary artery trunk, duplicated right renal pelvis, patent urachus with fistula, vaginal ectopia of the urethral meatus, abnormally shaped bladder neck with low implanted ureters, and bilateral vesicoureteral reflux. Despite the absence of neurological or endocrinological dysfunction, Pallister-Hall syndrome was suspected clinically. Neuro- 

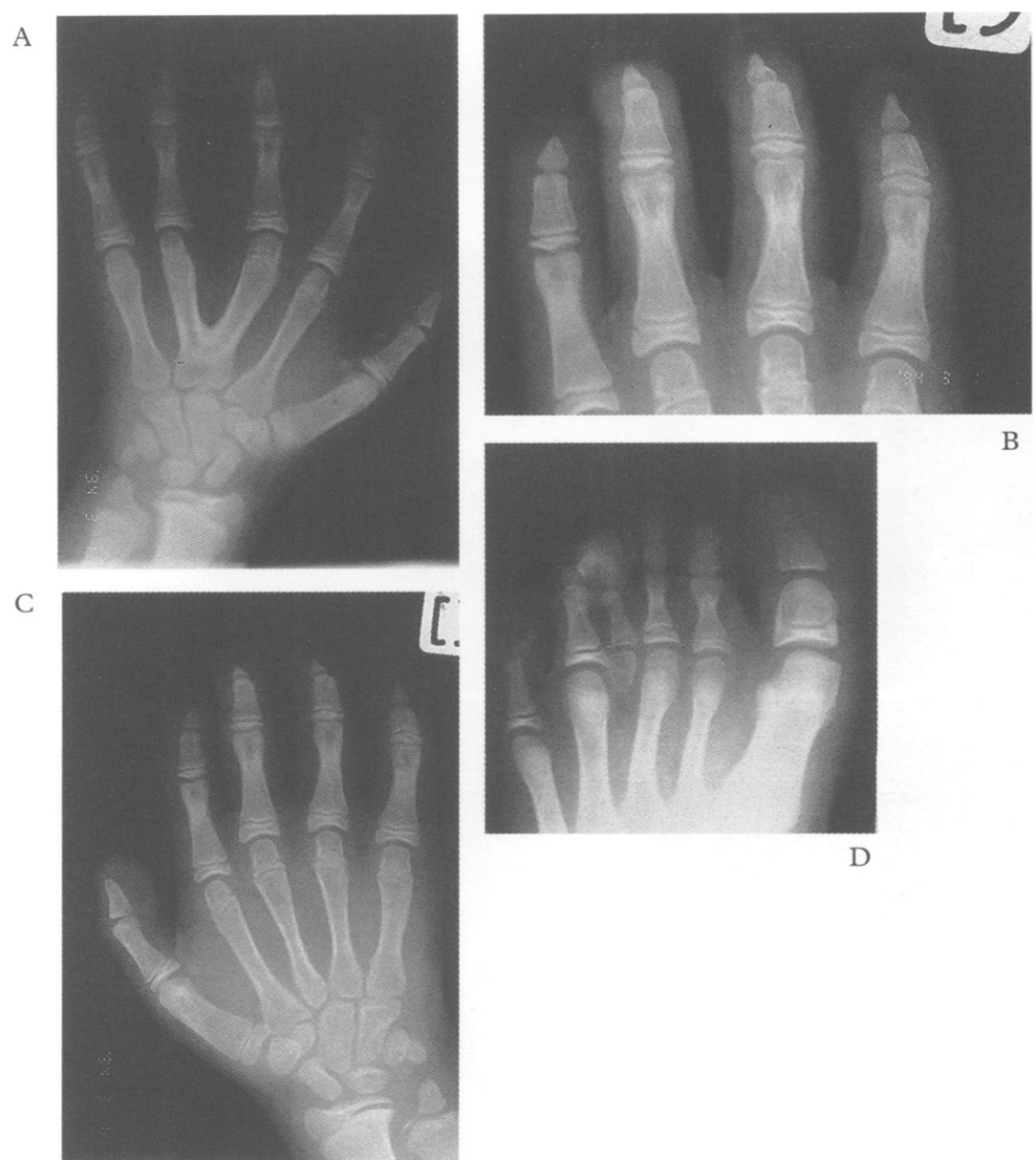

Figure 2 Patient 1. $X$ rays of the extremities at the age of 10. Left hand $(A)$ forked central metacarpal, (B) close up view of the distal phalanges, $(C)$ right hand: note epiphyseal irregularities in ulna and radius, (D) left foot: intercalated toe with missing proximal metacarpal. radiological investigations showed a homogeneous, solid, and poorly vascularised spherical mass extending from the floor of the 3 rd ventricle to the region of the tuber cinereum. This tumour compressed but did not interrupt the pituitary stalk. It was compatible with a hypothalamic hamartoma. Blood karyo-

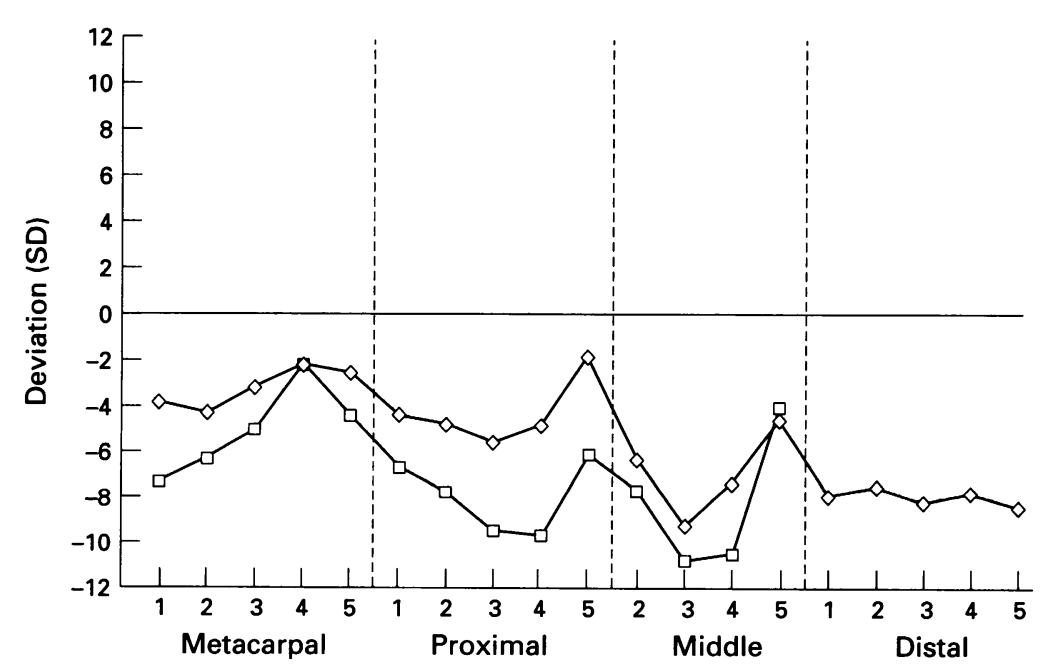

Figure 3 Metacarpophalangeal profile of patient 1 at the age of 10 (diamonds) and patient 2 at the age of 2 (squares). Distal phalanges could not be measured in patient 2.

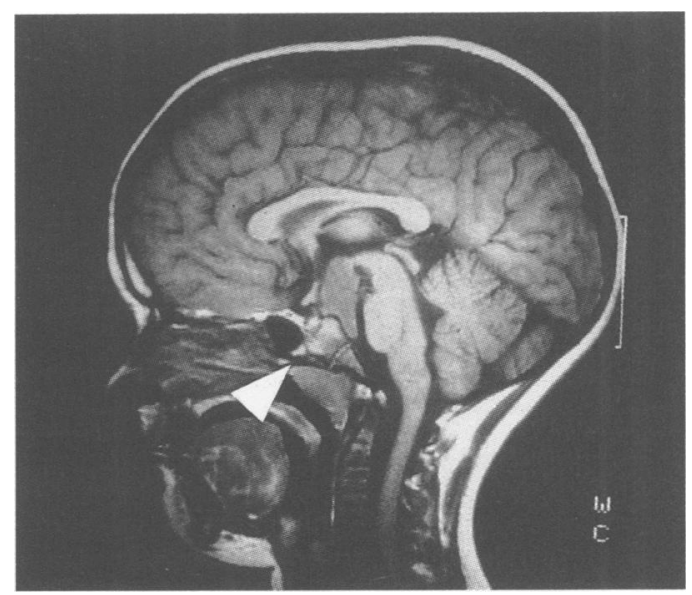

Figure 4 Patient 1. MRI scan of the proband: the tumour bulges in front of the cerebral peduncles.

type; serum cholesterol, and cholesterol metabolites were normal.

Despite laser excision of the malformed epiglottis, gastrostomy, and colostomy, the postnatal course was complicated by chronic respiratory and gastrointestinal problems resulting in failure to thrive. Although the weight curve paralleled $-3 \mathrm{SD}$, height was constantly at or below $-4 \mathrm{SD}$. OFC was proportionately less affected, being 2 SD below the mean for age. Partly owing to the physical handicaps, motor development was more delayed (sitting alone at 15 months, pulling self to standing and walking at 17 months) than social and play capabilities. At the age of 20 months (fig 6), she was alert and interested in her surroundings. Despite the hand malformations, she was able to build towers of four or five cubes. Although speech comprehension seemed quite adequate, expressive speech was proportionately delayed, and consisted of monosyllables. Her body temperature was constantly low, usually $35.3^{\circ} \mathrm{C}$. She died unexpectedly at the age of 2 of intractable glottic oedema following intubation for surgical revision of her colostomy. Macroscopic examination at necroscopy showed, in addition to the previously described findings, the following: proximal tracheo-oesophageal fistula, malformed laryngeal cartilages, bilateral incomplete pulmonary segmentation, undeveloped posterior mitral valve leaflet, ectopic kidneys, thyroid hypoplasia, adrenal hypoplasia, small pancreas, bifid uterus with ovaries present, imperforate vagina, and a presacral cyst. Visual inspection of the brain confirmed the presence in the tuber region of a grey, polylobulate, $2 \mathrm{~cm}$ wide tumour that compressed the optic chiasma.

$X$ rays of the extremities (fig 6 A-D) showed impressive brachydactyly. All metacarpals were short, the 1st being bilaterally very small. On the left side, the 3rd metacarpal was malformed and partially forked, its outer branch articulating with the hypoplastic 4th metacarpal. The proximal phalanges were short and ovoid. The middle phalanges were severely hypoplastic, almost punctiform. Distal phalanges were not visible and still not calcified at 20 months. In the feet, minute proximal phalanges were visible. The external ones were even less 

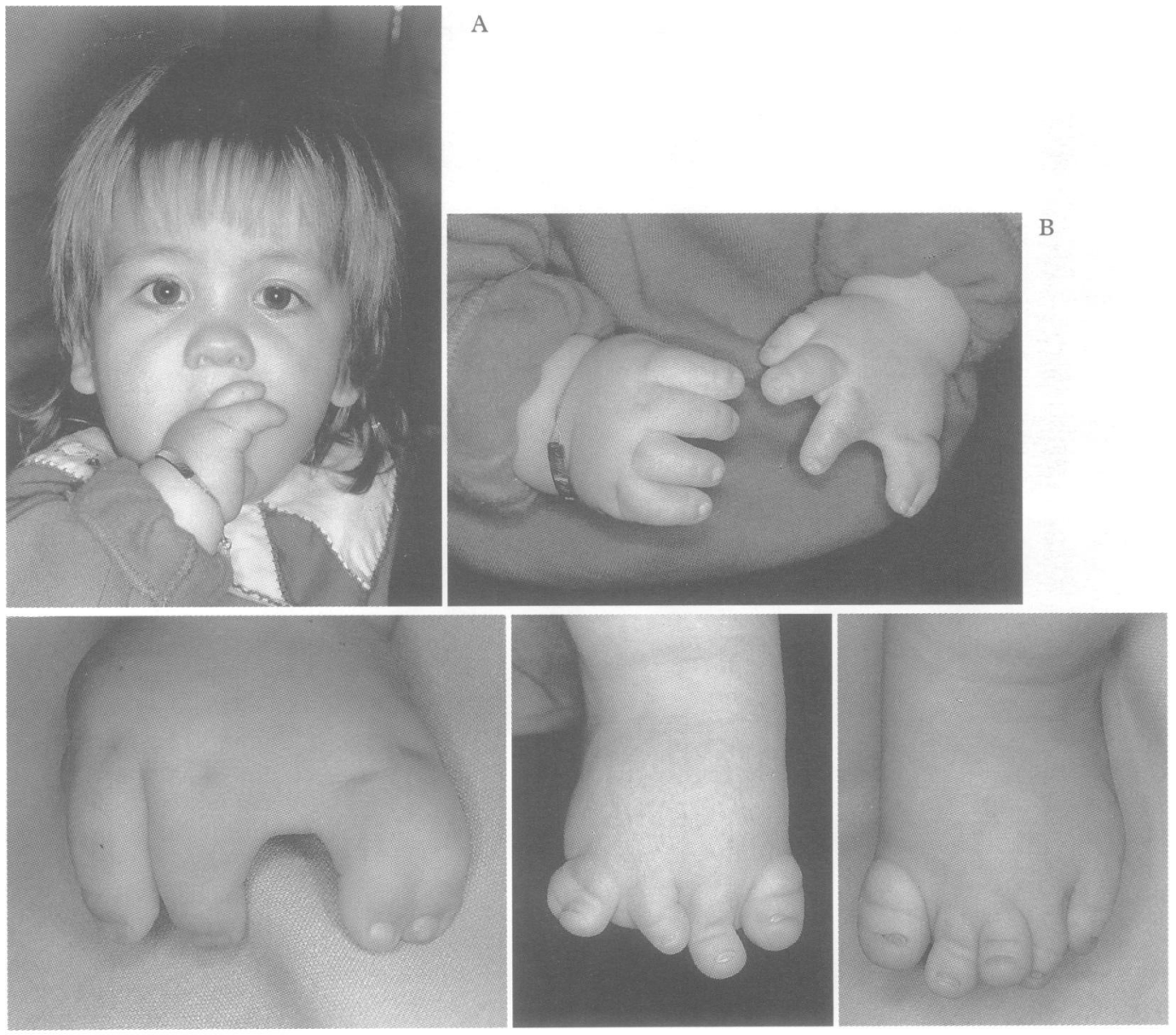

$\mathrm{D}$

E

Figure 5 Patient 2 aged 2. (A) Facial appearance: note apparent hypertelorism, flat nasal bridge, and downward slanted palpebral fissures, (B) upper extremities showing fingers of even length. Close up view of $(C)$ the left hand and $(D, E)$ feet: note nail hypoplasia.

developed. The first metatarsal bones were short and abnormally shaped. The 3rd left metatarsal was very hypoplastic and thin, and appeared intercalated between metatarsals 2 and 4 . On the right side, the four metatarsals were present. The missing 4 th ray was reduced to a single, proximal, barely visible phalanx. Other radiological findings included a generalised, moderate mesomelic shortening of the long bones, bilateral proximal radial subluxation, and normal spine and pelvis. $X$ rays of the father's hand did not show any structural abnormality and his MCPP profile was unremarkable.

\section{Discussion}

In 1980 , Hall et $a l^{1}$ reported six children, five of whom had a proven hypothalamic hamartoblastoma. All these children had multiple malformations, and the authors suggested that they could represent a new entity, possibly as a result of an exogenous agent. Following this report, many children were described with the "Pallister-Hall syndrome", although it clearly appeared that the patients reported with that diagnosis had very heterogeneous manifestations. Donnai et al ${ }^{2}$ suggested that PallisterHall syndrome was a variant of Smith-LemliOpitz syndrome type 2. Iafolla et $a l^{3}$ in an attempt to define Pallister-Hall syndrome, wrote that "the hallmark of Pallister-Hall syn- drome is the presence of a hamartoma considered as an obligatory manifestation of the syndrome", a statement that contradicts the "first axiom" of syndromology, namely that no component part of an MCA syndrome is expected to be present in all cases. The debate was further complicated by the publication of several cases of purported Pallister-Hall syndrome with unusual features, or overlapping with other syndromes. The nosology of Pallister-Hall syndrome is thus confused. Reviewing syndromal forms of hypothalamic hamartoblastoma, we tried to indicate the subjectivity, in many cases, of the diagnosis of Pallister-Hall versus another syndrome, depending on the criteria considered as major or minor for differential diagnosis. ${ }^{4}$ We suggested that, on clinical grounds alone, many of these patients could have more than one diagnosis, and coined the eponym CAVE (Cerebro-Acro-VisceralEarly lethality) as a group term for these ambiguous cases.

Recently, using multivariate analysis and numerical taxonomy we concluded that most overlapping cases (and, in fact, most cases reported as Pallister-Hall, including some from the original report) could be unambiguously classified as SLO 2, OFD VI, or holoprosencephaly-polydactyly syndrome. ${ }^{5}$ Only a few cases shared sufficient common features to be considered as being "true" instances of Pallister-Hall syndrome. Those candidates 

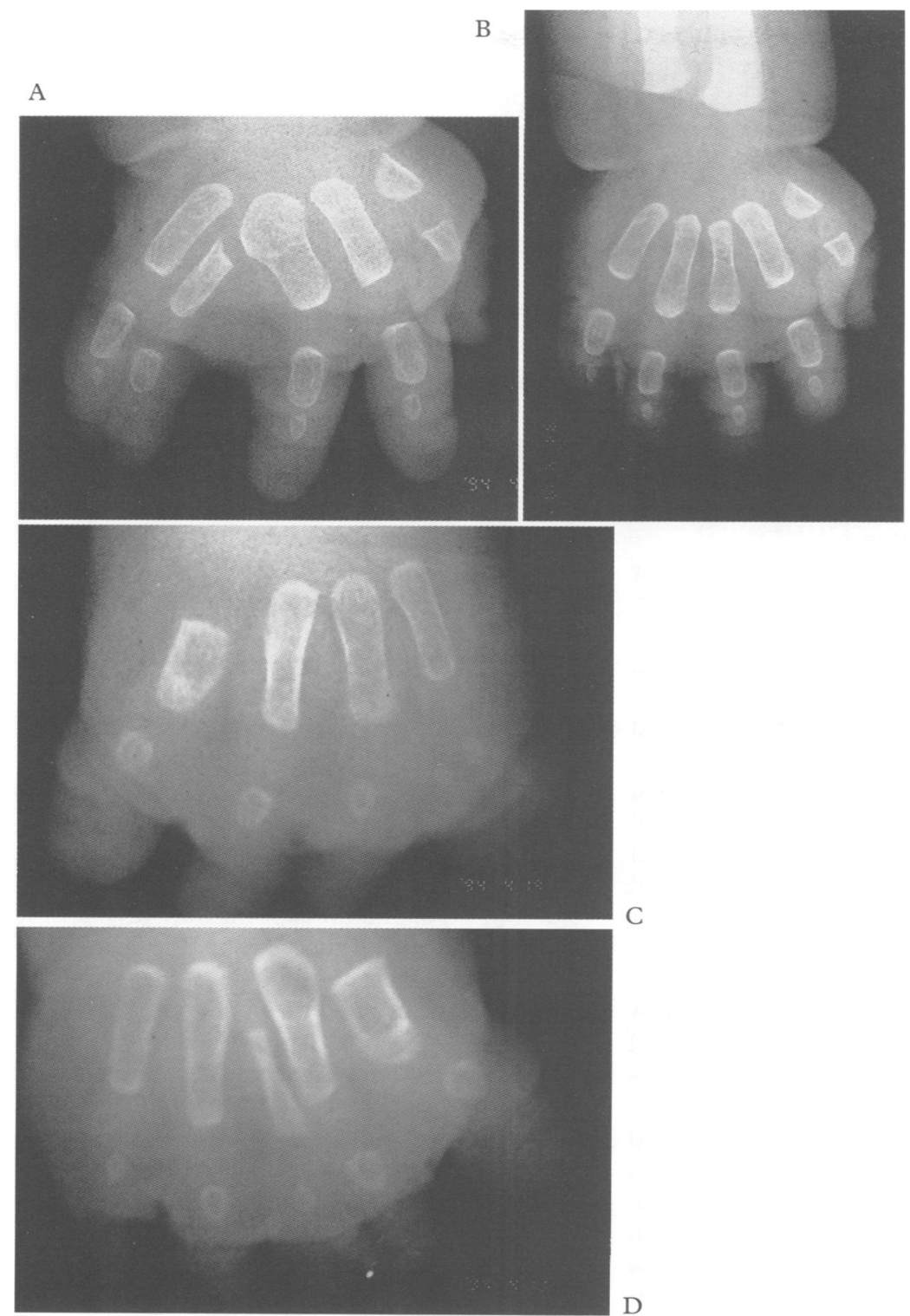

Figure 6 Patient 2. $X$ rays of the hands $(A, B)$ and feet $(C, D)$ at birth. Note lack of ossification of distal phalanges.

were cases 1,2 , and 4 , and probably case 5 of the original report, as well as case 1 of Iafolla et al. ${ }^{3}$ All those cases were sporadic. Patient 2 of this report resembles the cases of Hall et al. ${ }^{1}$ Patient 1 shows a milder phenotype. Orofacial involvement is minimal (neither frenula nor lingual anomalies), but kidney hypoplasia and cleft epiglottis were observed as in the original cases of Hall et al, ${ }^{1}$ the latter malformation being a feature of only a small number of other

Disorders recognised in children with a hypothalamic hamartoblastoma

\begin{tabular}{ll}
\hline Syndrome & Refenence \\
\hline Bardet-Biedl syndrome (?) & Bertelotti 1914, quoted by Warkany ${ }^{23}$ \\
Pallister-Hall & 1 \\
Frontonasal dysplasia & 24 \\
Hydrolethalus & 25 \\
Orofaciodigital syndrome type VI & 7 \\
Holoprosencephaly-polydactyly & 2,26 \\
Unknown skeletal dysplasia* & Case 1 in 27 \\
Orofaciodigital syndrome type IV* & Case 2 in 27 \\
Meckel syndrome & Case 3 in 27 \\
Unbalanced t(3;7) & 18 \\
Orofaciodigital syndrome type I & 28 \\
Microgastria-limb hypogenesis, severe form & 26 \\
Neurofibromatosis & 23 \\
Tuberous sclerosis & 23 \\
\hline
\end{tabular}

* Diagnosis suggested in LDDB v3, also supported by the authors. syndromes, such as Opitz BBBG syndrome. The hands and feet show a striking pattern of central anomalies and brachytelephalangism as in the cases of Hall et al. ${ }^{1}$

Apart from Hall et al ${ }^{1}$ no other authors have paid great attention to the precise pattern of acral abnormalities of the Pallister-Hall syndrome. Hall et al wrote: "the most striking changes were in and around the fourth metacarpal (and metatarsal), and involved hypoplasia as well as duplication". Short 4th metacarpal, distal phalangeal hypoplasia, nail hypoplasia, and brachydactyly were also conspicuous features of the original cases. These abnormalities were poorly described or overlooked and actually often missing in many subsequent reports.

The combination of intercalary defects and extreme brachytelephalangism, as observed in the present cases, appears highly specific for Pallister-Hall syndrome, and we think that this combination of anomalies is the most characteristic features of the syndrome. Central poly/syndactyly is extremely infrequent in other MCA syndromes. Resides PallisterHall cases, it is observed in OFD VI, and exceptionally in SLO 2. OFD VI shows V or $\mathrm{Y}$ shaped central metacarpals with ${ }^{67}$ or without ${ }^{8}$ polydactyly, and preaxial polydactyly of the feet, but they do not have brachydactyly comparable to that in Pallister-Hall syndrome. Case 1 of Le Merrer et al had typical SLO 2 with 3-4 and 5-6 synostoses of the feet. It has recently been shown that SLO patients (both with mild and severe forms) suffer a defect in 7-dehydrocholesterol (7DHC)lambda-7 reductase. ${ }^{10}$ This test now allows easy discrimination of SLO from Pallister-Hall syndrome as our patients had no anomalies of cholesterol biosynthesis (data on cholesterol anomalies in OFD VI have not yet been published). Cleper $e t a l^{11}$ reported two cousins born to an inbred family with an unclassifiable OFD syndrome overlapping OFD VI and Opitz trigonocephaly syndrome. The overall appearance fitted OFD VI but there was no anomaly of the cerebellar vermis. One of the children showed a supernumerary digit intercalated between the 3 rd and the 4 th, without brachydactyly.

Survival of children with hypothalamic hamartoblastoma and MCA, whatever syndromal diagnosis they present, is usually poor. Visceral malformations and hypothalamic-pituitary insufficiency (mainly adrenal insufficiency) are usually responsible for early death. Survival beyond infancy is exceptional. Besides the reports of Topf et $a l^{12}$ and Penman Splitt et $a l^{13}$ we found only two other long survivors: Greenhaw $e t$ al ${ }^{14}$ briefly reported a 24 year old boy, and Sills et $a l^{15}$ a living 4 year old boy. Neurological outcome of those cases seems unpredictable: the patient of Sills et $a l^{15}$ had normal intelligence; the case of Greenhaw et $a l,{ }^{14}$ despite severe expression (anal atresia, Hirschsprung disease), had moderate mental retardation, epilepsy, and partial hypopituitarism, and our own patients are mentally impaired. Endocrine disturbances are also unpredictable, but partial or total hypo- 
pituitarism and central precocious puberty are common disturbances, as in the case of hamartomas without MCA. ${ }^{16}$ These observations of long survival show that the prognosis of syndromal hamartoblastoma of the hypothalamus is not universally fatal, and that early adequate neurosurgical and endocrinological management of the affected children could result in a better survival rate.

The genetics of Pallister-Hall syndrome remain unclear, most cases being sporadic. A teratogenic aetiology was initially postulated. ${ }^{1}$ Later, autosomal recessive and dominant inheritance have been proposed. Recurrence in sibs would be in favour of a recessive mode of inheritance, but the diagnosis in these reported cases does not fit our criteria. ${ }^{11}{ }^{1518-20}$

Three convincing reports, with among other findings evidence of male to male transmission, support autosomal dominant inheritance of Pallister-Hall syndrome. A 9 year old boy and his 34 year old father were reported. ${ }^{12}$ The child had a hamartoblastoma, midaxial and postaxial polydactyly with brachydactyly (no $x$ rays shown), hypospadias, imperforate anus, and precocious puberty. His father had central and postaxial polydactyly, macrocephaly, and a hypothalamic mass. Both were of normal intelligence. A 26 year old mother and her newborn daughter were recently described. ${ }^{13}$ The child died at 18 hours; she had a hypothalamic mass and her pituitary gland was absent. Malformations included postaxial polysyndactyly with acromesomelic limb shortening, brachydactyly (no $x$ rays), ASD, cleft larynx, and renal hypoplasia. Her mother had acromesomelic shortening of all limbs with impressive brachydactyly and nail hypoplasia, polysyndactyly, fused 3rd and 4th metacarpals, intercalary type of polydactyly of one foot and four metacarpals in the other foot, bifid epiglottis, bifid renal pelvis, subnormal intelligence (IQ 82), and no clinical evidence of hypothalamohypophyseal dysfunction (the patient declined neuroimaging). Her facial appearance at the age of 1 is strikingly similar to our case 2 . Thomas et $a l^{19}$ reported the third familial observation. Two sibs were severely affected. They died during their first year. Both had a cleft larynx, abnormal pulmonary lobes, choanal stenosis/atresia, and a hamartoma of the hypothalamus with hypopituitarism. The girl had short tapering fingers, short terminal phalanges and nails (on pictures), and hexadactyly with, on one side, a synostosis of metacarpals 2 and 3 (described, but not illustrated as central polydactyly). Her brother had 4-5 syndactyly, postaxial polydactyly, brachydactyly more severe in the 4th and 5th rays, hypoplastic middle finger, hypoplastic 4 th metacarpal, and a synostosis of metacarpals 2 and 3. Postaxial polydactyly and 4-5 syndactyly were present in the father, who had no other abnormalities. The authors considered the possibility of a very mild expression or gonosomal mosaicism for a dominant gene to explain the milder signs in the father and the transmission of the condition to his offspring. They further hypothesised that most sporadic cases might represent new dominant mutations. Sills $e t \mathrm{al}^{15}$ also evoked the theoretical possiblity of germinal mosaicism. As an alternative explanation, the authors could not exclude the segregation in the familial cases of a submicroscopic chromosome abnormality. In our report, the advanced paternal age in patient 1 and the postaxial polydactyly in the father of patient 2 are further arguments in favour of a dominant gene mutation causing Pallister-Hall syndrome. This issue is of obvious importance for genetic counselling, as Pallister-Hall syndrome appears to be inherited differently from most of the other disorders with hamartoblastoma listed in the table.

Kuller et $a l^{18}$ reported two sibs suspected to have Pallister-Hall syndrome. The proband was karyotyped: he had the der(7) chromosome of a paternal $t(3 ; 7)(\mathrm{p} 25 ; \mathrm{q} 36)$ translocation. These sibs had holopresencephaly sequence, median cleft, colobomatous microphthalmia, no polydactyly, and at least in one case, a hypothalamic hamartoma. Oral anomalies, if present, were not described. Whether they truly had Pallister-Hall syndrome in our narrower sense remains dubious. The recent mapping of genes for a dominantly inherited complex bilateral polysyndactyly ${ }^{21}$ and for dominant thumb triphalangism in the same subtelomeric region of $7 \mathrm{q}$ as the breakpoint may be relevant to the discussion of the possible localisation of the Pallister-Hall gene.

In conclusion, the pattern of acral anomalies is helpful in selecting "true" Pallister-Hall syndrome cases and in differential diagnosis. Combined with the oral and laryngeal malformations and the lower digestive tract abnormalities, central polysyndactyly and brachytelephalangism should allow the recognition of Pallister-Hall syndrome in the strictest sense even without CNS tumours in children for whom an inborn error of cholesterol metabolism has been ruled out.

The authors wish to express their gratitude to the parents of the reported children, and to Drs D Nussle, P Bugmann, C Le Coultre, and P Monnier for their care of patient 2.

1 Hall JG, Pallister PD, Clarren SK, Beckwith JB, Wiglesworth FW, et al. Congenital hypothalamic hamartoblastoma, hypopituitarism, imperforate anus, and postaxial polyhypopituitarism, imperforate anus, and postaxial polydactyly - a new syndrome? Part 1: clinical, causal and

2 Donnai D, Burn J, Hughes H. Smith-Lemli-Opitz syndromes: do they include Pallister-Hall syndrome? $A m \mathfrak{F}$ dromes: do they include Pa.

3 Iafolla K, Fratkin JD, Spiegel PK, Cohen MMJ, Graham JMJ. Case report and delineation of the congenital hypothalamic hamartoblastoma syndrome (Pallister-Hall syndrome). Am $\mathcal{F}$ Med Genet 1989;33:489-99.

4 Verloes A, Gillerot Y, Langhendries JP, Fryns JP, Koulischer L. Variability versus heterogeneity in syndromal hypothalamic hamartoblastoma and related disorders: review and delineation of the cerebroacrovisceral early lethality (CAVE) multiplex syndrome. Am $\mathcal{F}$ Med Genet 1992;43: 669-77.

5 Verloes A. Numerical syndromology. A mathematical approach to the nosology of complex phenotypes. $\mathrm{Am} \mathcal{F} \mathrm{Med}$ Genet 1995;55:433-43.

6 Varadi V, Szabo L, Papp Z. Syndrome of polydactyly, cleft lip/palate or lingual lump, and psychomotor retardation in endogamic gypsies. 7 Med Genet 1980;17:119-22.

7 Münke M, McDonald DM, Cronister A, et al. Oral-facialdigital syndrome type VI (Varadi syndrome): further clindigital syndrome type VI (Varadi syndrome): further

8 Mattéi JF, Aymé S. Syndrome of polydactyly, cleft lip, lingual hamartomas, renal hypoplasia, hearing loss, and psychomotor retardation: variant of the Mohr

9 Le Merrer M, Briard ML, Girard S, et al. Lethal acrodysgenital dwarfism: a lethal condition resembling rodysgenital dwarfism: a lethal condition resembling
Smith-Lemli-Opitz syndrome. $f$ Med Genet 1988;25:8895 . 
10 Tint GS, Irons M, Elias ER, et al. Defective cholesterol biosynthesis associated with the Smith-Lemli-Opitz syndrome. N Engl F Med 1994;330:107-13.

11 Cleper R, Kauschansky, A, Varsano I, Frydman M. Varadi syndrome (OFD VI) or Opitz trigonocephaly syndrome: overlapping manifestations in two cousins. $A m \mathcal{F} M e d$ Genet 1993;47:451-5.

12 Topf KF, Kletter GB, Kelch RP, Brunberg JA, Biesecker LG. Autosomal dominant transmission of the PallisterLG. Autosomal dominant transmission of

13 Penman Splitt M, Wright C, Perry R, Burn J. Autosomal dominant transmission of Pallister-Hall syndrome. Clin dominant transmission of
Dysmorphol 1994;3:301-8.

14 Greenhaw G, Orlander P, Langford L, Horton W. Longterm survival in Pallister-Hall syndrome. Am $\mathcal{F}$ Hum Genet (Suppl) 1991;49:138.

15 Sills I, Rapaport R, Robinson LP, et al. Familial PallisterHall syndrome: case report and hormonal evaluation. $\mathrm{Am}$ f Med Genet 1993;47:321-5.

16 Starceski PJ, Lee PA, Albright AL, Migeon CJ. Hypothalamic hamartoma and sexual precocity. $\mathrm{Am} F \mathrm{Di}$ Child 1990;144:225-8.

17 Zuniga OF, Tanner SM, Wild WO, Mosier HDJ. Hamartoma of the CNS associated with precocious puberty. Am $\mathcal{F}$ Dis Child 1983;137:127-33.

18 Kuller JA, Cox VA, Schonberg SA, Golabi M. Pallister-Hall syndrome associated with an unbalanced chromosomal translocation. Am $\mathcal{F}$ Med Genet 1992;43:647-50.

19 Thomas HM, Todd PJ, Heaf D, Fryer AE. Recurrence of Pallister-Hall syndrome in two sibs. Am $\mathcal{F}$ Med Genet 1994;51:145-7.

20 Sills IN, Rapaport R, Desposito F, Lieber C. Familial
Pallister-Hall syndrome: three affected offspring. $A m \mathcal{f}$ Med Genet 1994;52:251.

21 Tsukurov O, Boehmer A, Flynn J, et al. A complex bilateral polysyndactyly disease locus maps to chromosome $7 \mathrm{q} 36$. Nature Genet 1994;6:287-92.

22 Heutink P, Zguricas J, van Oosterhout L, et al. The gene for triphalangeal thumb maps to the subtelomeric region of chromosome 7q. Nature Genet 1994;6:287-92.

23 Warkany J. Congenital malformations: notes and comments. Chicago: Year Book Medical Publisher, 1971.

24 Hennekam RCM, Beemer FA, Van Merrienboer F, Van Ketel BA, Kramer PPG. Congenital hypothalamic hamartoblastoma associated with severe midline defect: a developmental field defect. Am $\mathcal{F}$ Med Genet 1986;suppl developm

25 Anyane-Yeboa K, Collins M, Kupsky W, et al. Hydrolethalus (Salonen-Herva-Norio) syndrome: further clinicopathological delineation. Am $\mathcal{F}$ Med Genet 1987;26:899907.

26 Verloes A, Narcy F, Fallet-Bianco C. Syndromal hypothalamic hamartoblastoma with holoprosencephaly sequence, microphthalmia, pulmonary malformations, radial hypoplasia and Müllerian regression. Further delineation of a new syndrome? Clin Dysmorphol 1995; 4:33-7.

27 Encha-Razavi F, Larroche JC, Roume J, et al. Congenital hypothalamic hamartoma syndrome. Nosological discussion and minimum diagnostic criteria of a possible familial form. Am $\mathcal{F}$ Med Genet 1992;42:44-50.

28 Somer M, Lindahl E, Perheentupa J. Precocious puberty associated with oral-facial-digital syndrome type 1. Acta associated with oral-facial-digi
Paediatr Scand 1986;75:672-5. 